\title{
Lipid Metabolism and Cardiovascular Risk in HIV-1 Infection and HAART: Present and Future Problems
}

\author{
Sara Melzi, ${ }^{1}$ Laura Carenzi, ${ }^{1}$ Maria Vittoria Cossu, ${ }^{2}$ Simone Passerini, ${ }^{1}$ \\ Amedeo Capetti, ${ }^{1}$ and Giuliano Rizzardini ${ }^{1}$ \\ ${ }^{1}$ 1st Division of Infectious Diseases, "Luigi Sacco" Hospital, Via GB Grassi, 74, 20157 Milan, Italy \\ ${ }^{2}$ Clinical Pharmacology Unit, "Luigi Sacco" Hospital, 20157 Milan, Italy
}

Correspondence should be addressed to Giuliano Rizzardini, rizzardini.giuliano@hsacco.it

Received 28 April 2010; Revised 15 August 2010; Accepted 7 September 2010

Academic Editor: Gloria L. Vega

Copyright (C) 2010 Sara Melzi et al. This is an open access article distributed under the Creative Commons Attribution License, which permits unrestricted use, distribution, and reproduction in any medium, provided the original work is properly cited.

\begin{abstract}
Many infections favor or are directly implicated with lipid metabolism perturbations and/or increased risk of coronary heart disease (CHD). HIV itself has been shown to increase lipogenesis in the liver and to alter the lipid profile, while the presence of unsafe habits, addiction, comorbidities, and AIDS-related diseases increases substantially the risk of cardiovascular disease (CVD) in the HIV-infected population. Antiretroviral therapy reduces such stimuli but many drugs have intrinsic toxicity profiles impacting on metabolism or potential direct cardiotoxicity. In a moment when the main guidelines of HIV therapy are predating the point when to start treating, we mean to highlight the contribution of HIV-1 to lipid alteration and inflammation, the impact of antiretroviral therapy, the decisions on what drugs to use to reduce the probability of having a cardiovascular event, the increasing use of statins and fibrates in HIV-1 infected subjects, and finally the switch strategies, that balance effectiveness and toxicity to move the decision to change HIV drugs. Early treatment might reduce the negative effect of HIV on overall cardiovascular risk but may also evidence the impact of drugs, and the final balance (reduction or increase in CHD and lipid abnormalities) is not known up to date.
\end{abstract}

\section{CHD and Infections}

By the turn of the last century, medicine abandoned the link between infection, metabolic disorders, and atherogenesis because it did not fit in with the trends of the medical establishment convinced that chronic diseases such as heart disease must be multifactorial, degenerative, and noninfectious. Today, many patients with heart disease do not have the classic risk factors such as hypercholesterolemia, hypertension, smoking, or obesity; so it is not inconsistent that infection might underlie such damage.

It is now generally recognised that cytokines, especially TNF, interleukin-1, and interleukin-6, which mediate the host acute-phase response to infection and inflammation, also mediate changes in lipid metabolism.

Several studies have addressed the possible role of infectious agents, both bacteria and viruses, in the pathogenesis of coronary heart disease and atherosclerosis [1, 2]. The concept of pathogen burden as a risk factor for CHD was first introduced by Epstein and his collaborators [3].
Both acute and chronic infections could play a role in the development of atherosclerosis and CHD. Acute infections (i.e., Coxsackie B viruse-induced myocarditis) could trigger acute cardiovascular events, and an acute respiratory infection during the 2 preceding weeks has been shown to be a risk factor for AMI in people with no history of classic risk factors [4].

Chronic infections may actively participate in the atherosclerotic process, leading to continuous low-level production of cytokines and thus to an atherogenic lipid profile, increasing triglyceride and total cholesterol, and lowering HDL concentrations [5]. Via their effect on lipid and glucose metabolism, chronic infections might also be related with obesity and the metabolic syndrome [6].

People infected with multiple pathogens, such as HSV1, HSV-2, CMV, H. pylori, C. pneumoniae, and hepatitis A virus have high $\mathrm{C}$-reactive protein rates as a marker of inflammation-a major relative risk factor for coronary artery disease [7] —and serological association between enteroviruses and human CHD has been suggested [8]. 
Finally, mycobacterial diseases share interesting connections to heart disease because the pathogenesis of tuberculosis depends on cholesterol and atypical tuberculosis caused elevation of C-reactive Protein, interleukin-6, and homocysteine 2 [9].

\section{Dyslipidemia and HIV-1 Infection}

2.1. In Vitro Studies. HIV-1 infection causes a specific pattern of dyslipidemia, resulting from a combination of increased production and decreased clearance of lipoproteins. Molecular mechanisms responsible for the numerous lipid-related disorders in HIV-infected individuals are not well understood. Adipose tissue hosts multiple cell types including monocytes, macrophages, endothelial and vascular smooth muscle cells. These immune cells are functionally active in the adipose tissue and produce numerous cytokines and other regulatory factors that influence lipid homeostasis, regulation of steroid hormones, prostaglandin, and fatsoluble vitamins. These factors also control storage of excess lipids and triglycerides (either normal and abnormal fatty acids) present in the circulation. Many infectious agents including HIV-1 have profound impact on adipocytes which become dysfunctional and cannot store most lipids-that is, triglycerides-properly.

Rasheed et al. [10] present the first direct evidence that HIV replication alone in human T-cells, without any influence of antiviral drugs or other factors, can stimulate the production of novel cellular enzymes and proteins that enhance fatty acid synthesis, increase the quantity of low density lipoproteins, secrete triglycerides, alter the lipid transport and metabolism, and oxidize lipids. This finding leads us to a new concept in HIV-1 pathogenesis. One of the most essential biological processes involved in dyslipidemia and lipodystrophy syndrome is the accumulation of lipids and disproportionate distribution of tissue-associated fats due to the enhanced fatty acid synthesis. Since kinases and enzymes activate most cellular functions including lipid synthesis, Rasheed first analyzed the functional significance of these proteins in HIV-infected cells in comparison with those expressed in the uninfected control cells.

They discovered that of the 18 differentially expressed proteins in HIV-infected cells, six enzymes/kinases were expressed exclusively in HIV-infected cells (CO3, P3C2B, KPCB, FAS, ACSL1, and GPX1) and one isomerase (PDIA3) was slightly downregulated after chronic HIV infection. They conclude that HIV-1 replication alone (i.e., without any influence of antiviral drugs or other human genetic factors) can induce novel cellular enzymes and proteins that are significantly associated with biologically relevant processes involved in lipid synthesis, transport, and metabolism $(P=$ $.0002-.01)$. This is the first direct evidence that HIV-1 modulates the production of proteins that are significantly involved in disrupting the normal metabolic pathways of lipids. However, the study presents several possible biases because it is not clear if the result would be the same with real cells; besides only $\mathrm{X} 4$ virus was studied which may not reflect the in vivo situation, mainly characterised by R5-tropic virus.
Furthermore, polybrene was used to infect the cells, which artificially helps to bypass surface binding and entry by the virus.

Translational and clinical studies on the newly discovered proteins may now shed light on how some of these proteins may be useful for early diagnosis of individuals who might be at high risk for developing lipid-related disorders. The target proteins could then be used for future studies in the development of inhibitors for preventing lipid-metabolic anomalies.

2.2. In Vivo Studies. Hellerstein et al. [11] measured de novo lipogenesis in three groups of patients (HIV-infected with history of weight loss, asymptomatic HIV-infected, and uninfected males) and found that hepatic lipogenesis was three to fourfold higher in the first group compared with seronegative controls $(P<.05)$. The authors concluded that HIV infection was associated with abnormal fat anabolism.

Riddler et al. [12] evaluated changes in serum cholesterol associated with HIV infection and subsequent antiretroviral therapy, testing saved blood samples on 50 of 517 male seroconverters from the Multicenter AIDS Cohort Study. The outcome measures were changes in total cholesterol (TC), high-density lipoprotein cholesterol (HDL-c), and lowdensity lipoprotein cholesterol (LDL-c). These parameters were evaluated at six time points over a period of 12 years. After HIV seroconversion, they noted significant declines in TC, HDL-c, and LDL-c. Following the initiation of HAART, increases in TC and LDL-c to slightly above preseroconversion levels were seen. The authors concluded that HIV infection alone results in substantial decrease in TC, HDL-c, and LDL-c. They postulated that the posttreatment elevations in TC and LDL-c probably represent a return to preinfection lipid levels.

Moreover, many additional factors may influence atherogenesis and CVD, such as AIDS-related infections [13] or the fact that certain "classical" vascular risk factors are overrepresented in the HIV-infected population (i.e., cigarette smoking). On the other hand, recent studies have shown that, similarly to the observation made in the general population, HCV coinfection seems to be associated with lower blood levels of cholesterol in HIV patients receiving ART [14].

\section{Cardiac Risk and HIV Infection}

Prior to the advent of HAART, infections and tumours were the prevalent causes of cardiovascular damage in HIV-1 infected subjects (pericarditis, miocarditis, endocarditis, and cardiac involvement in AIDS-related tumours). With the advent of HAART and the subsequent longer survival, the most common cardiovascular disease is ischemic disease [15].

However, it is not so clear to what extent antiretroviral therapy may increase or decrease the risk of cardiovascular disease (CVD). CVD, indeed, is more common in HIVinfected patients than HIV negative, mostly due to the higher prevalence of $\mathrm{CV}$ risk factors like metabolic abnormalities 
(dyslipidemia and insulin resistance) and drug consumption (tobacco, alcohol, cocaine) $[16,17]$. Moreover, HIV infects smooth muscle cells in vivo promoting inflammation [18] and ACTG 5152s showed that untreated HIV infection is associated with endothelial dysfunction, and ART restores the endothelial damage $[19,20]$.

The difficulties in determining the cardiac risk among HIV-infected patients have largely been due to the lack of matched controls and to small sample sizes.

\section{Cardiac Risk and Antiretroviral Therapy}

Although some drugs may be more harmful than others in increasing CVD risk, it is now clear that any therapy is better than no therapy.

In the largest trial of intermittent treatment, the SMART study, patients assigned to the intermittent therapy arm had a higher incidence of cardiovascular disease [21]. In the STACCATO study, the interruption of therapy was associated with increases in markers of endothelial dysfunction and inflammation contributing to the development of cardiovascular disease [22].

When choosing the drugs to build an antiretroviral regimen, however, not every drug or class of drugs is equivalent in terms of impact on the CVD risk.

The Data Collection on Adverse Events of Anti-HIV Drugs (D:A:D) investigators reported an increased relative rate (RR) of myocardial infarction (MI) with the cumulative use of protease inhibitors (RR per year of exposure, 1.16 [95\% confidence interval $\{\mathrm{CI}\}, 1.10-1.23]$ ) but not of nonnucleoside reverse transcriptase inhibitors (RR per year of exposure, 1.05 [95\% CI, 0.98-1.13]) [23]. In a subsequent analysis focusing on nucleoside reverse transcriptase inhibitor use, an unexpected increased risk of MI was found with recent use of abacavir (RR, 1.90 [95\% CI, 1.47-2.45]) and didanosine (RR, 1.49 [95\% CI, 1.14-1.95]), but not with cumulative use [24].

Many trials and nonsponsored studies have assessed the efficacy and the lipid profile of all the approved antiretrovirals and nowadays the metabolic impact of a new drug is considered as important as its potency.

The STEAL study evaluated the incidence of CVD over 96 weeks in patients treated with abacavir plus lamivudine (ABC/3TC) versus tenofovir plus emtricitabine (TDF/FTC). Patients assigned to the $\mathrm{ABC} / 3 \mathrm{TC}$ arm had significantly more cardiovascular events but unfortunately patients in $\mathrm{ABC} / 3 \mathrm{TC}$ had a heavier history of risk factors than patients assigned to TDF/FTC [25].

The BICOMBO study, another randomized trial of switching to the thymidine analogue-sparing fixed dose combinations (FDCs), showed only one case of myocardial infarction in a younger population with a lower baseline Framingham score [26].

The ACTG 5202 study, a multicenter, randomized, blinded equivalence study compared antiviral activity, safety, and tolerability of $\mathrm{ABC} / 3 \mathrm{TC}$ and TDF/FTC given with efavirenz or ritonavir-boosted atazanavir for the initial treatment of HIV-1 infection, followed for 96 weeks. A total of 1858 eligible patients were enrolled in the study from September 2005 to November 2007. This analysis includes data from 797 patients with a screening HIV-1 RNA level of 100,000 copies/mL or more. At week 48, fasting lipid levels had increased more in the patients who received $\mathrm{ABC} / 3 \mathrm{TC}$ than in the patients who received TDF/FTC (median change in TC level: 34 versus $26 \mathrm{mg} / \mathrm{dL}, P<.001$; HDL-c level: 9 versus $7 \mathrm{mg} / \mathrm{dL}, P=.05$; and triglyceride (TG) level: 25 versus $3 \mathrm{mg} / \mathrm{dL}, P=.001)$. There was no significant difference between groups in the change in the ratio of TC: HDL-c (median, -0.2 for both groups; $P=.50$ ) [27].

The GEMINI study, a 48-week, multicenter, open-label study, confirmed the noninferiority of a TDF/FTC backbone plus saquinavir/ritonavir (SQV/r) $1000 \mathrm{mg} / 100 \mathrm{mg}$ twice a day $(n=167)$ versus TDF/FTC plus lopinavir/ritonavir $(\mathrm{LPV} / \mathrm{r}) 400 \mathrm{mg} / 100 \mathrm{mg}$ twice a day $(n=170)$ in treatmentnaive HIV-1-infected adults.

The rate and severity of adverse events were similar in both groups. There were no significant differences in the median change from baseline between arms in plasma lipids except for triglyceride levels, which were significantly higher in the LPV/r arm at week 48 [28].

KLEAN is an open-label, noninferiority study including 878 antiretroviral-naive, HIV-1-infected patients randomised to receive either fosamprenavir-ritonavir $700 \mathrm{mg} /$ $100 \mathrm{mg}$ twice daily or lopinavir-ritonavir $400 \mathrm{mg} / 100 \mathrm{mg}$ twice daily, each with the coformulation of $\mathrm{ABC} / 3 \mathrm{TC}$. At week 48 , not only the noninferiority of fosamprenavirritonavir to lopinavir-ritonavir (95\% CI around the treatment difference -4.84 to 7.05 ) was shown, but also the metabolic impact of the two regimens was comparable [29].

In the CASTLE study, once-daily atazanavir/ritonavir ( $n=440)$ demonstrated similar antiviral efficacy as twicedaily lopinavir/ritonavir $(n=443)$, each combined with TDF/FTC. Treatment-related gastrointestinal adverse events were greater in patients taking lopinavir/ritonavir. Mean changes from baseline in fasting total cholesterol, non-highdensity lipoprotein cholesterol, and triglycerides at week 96 were significantly higher with lopinavir/ritonavir $(P<.0001)$ [30].

The ARTEMIS (AntiRetroviral Therapy with TMC114 ExaMined In Naive Subjects) trial, a randomized, openlabel, phase III trial of 689 antiretroviral-naive patients with HIV-1 RNA at least 5000 copies/ml (stratified by HIV1 RNA and CD4 cell count) receiving darunavir/ritonavir (DRV/r) 800/100 mg once daily or lopinavir/ritonavir (LPV/r) 800/200 mg total daily dose (twice daily or once daily) and TDF/FTC has disclosed 96-week data. DRV/r patients had smaller median increases in triglycerides $(0.1$ and $0.6 \mathrm{mmol} / \mathrm{L}$, resp.; $P<.0001)$ and total cholesterol $(0.6$ and $0.9 \mathrm{mmol} / \mathrm{L}$, resp.; $P<.0001)$ than $\mathrm{LPV} / \mathrm{r}$ patients; levels remained below National Cholesterol Education Program cut-offs for DRV/r. At week 96, once-daily DRV/r was both statistically noninferior and superior in virologic response to $\mathrm{LPV} / \mathrm{r}$, with a more favorable gastrointestinal and lipid profile, confirming DRV/r as an effective, well tolerated, and durable option for antiretroviral-naive patients [31]. 
Cholesterol

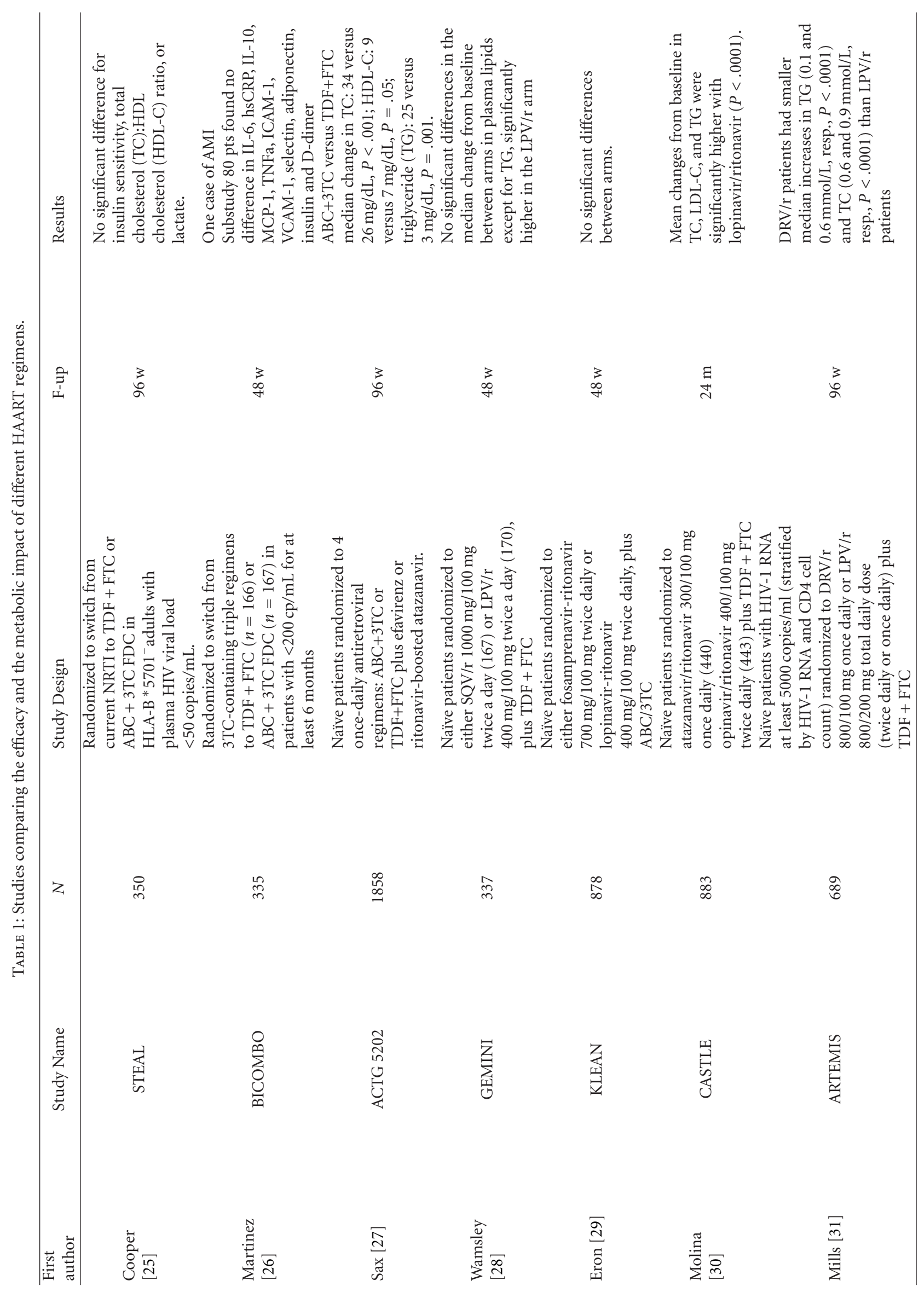




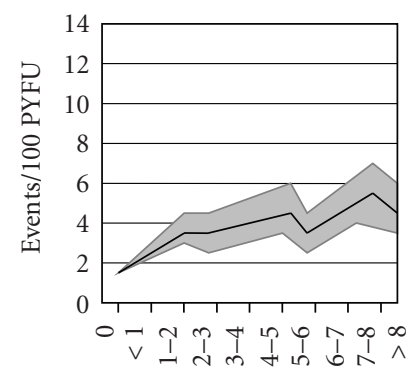

Exposure to zidovudine (years)

(a) Zidovudine

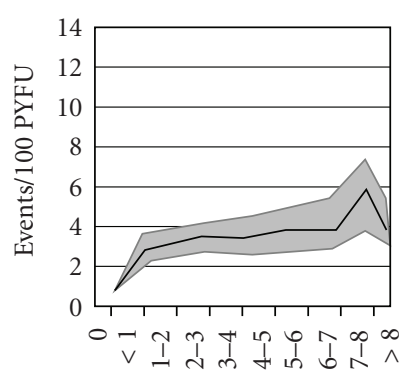

Exposure to lamivudine (years)

(e) Lamivudine

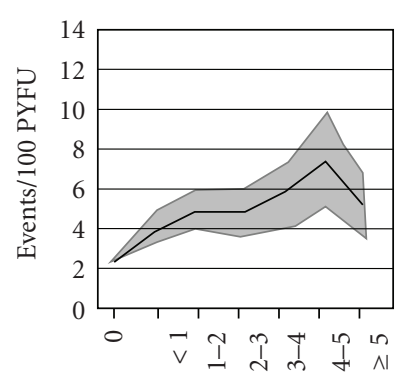

Exposure to indinavir (years)

(i) Indinavir

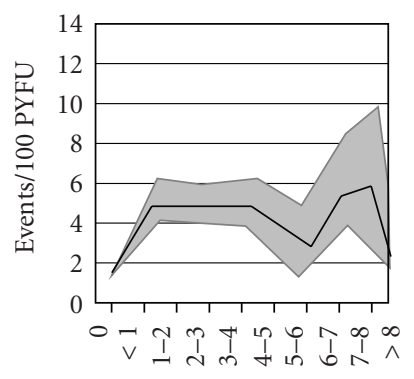

Exposure to didanosine (years)

(b) Didanosine

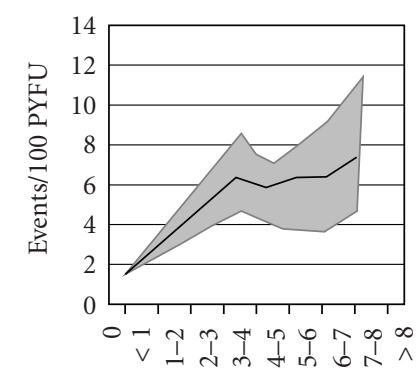

Exposure to abacavir (years)

(f) Abacavir

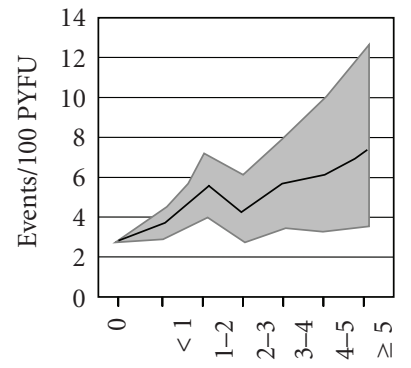

Exposure to lopinavir/r (years)

(j) Lopinavir/ritonavir

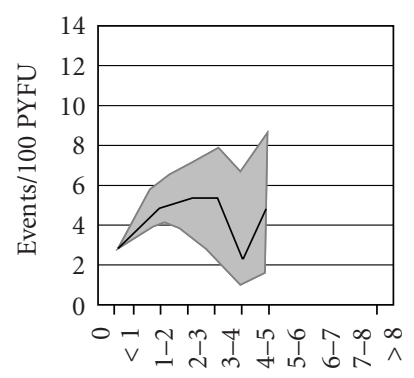

Exposure to zalcitabine (years)

(c) Zalcitabine

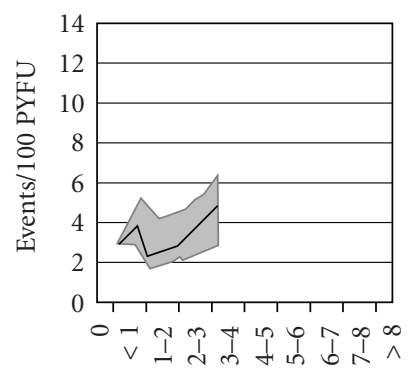

Exposure to tenofovir (years)

(g) Tenofovir

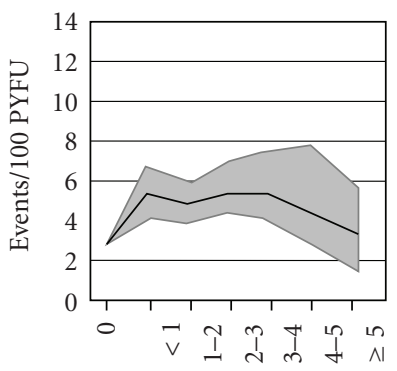

Exposure to saquinavir (years)

(k) Saquinavir

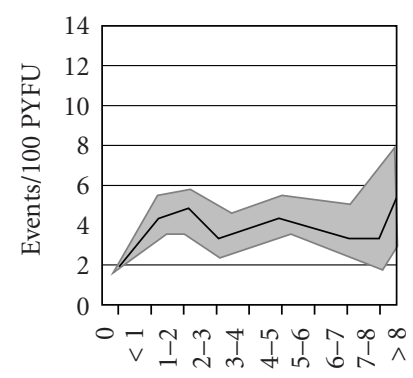

Exposure to stavudine (years)

(d) Stavudine

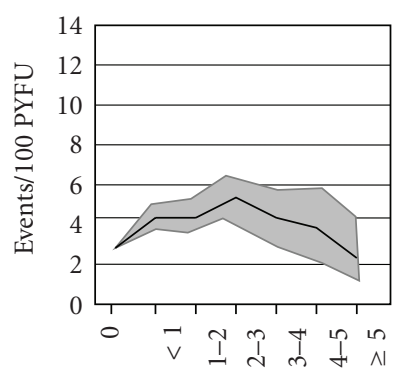

Exposure to nelfinavir (years)

(h) Nelfinavir

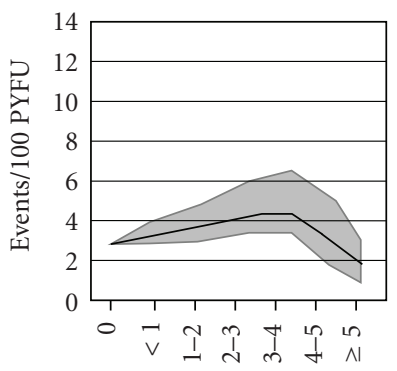

Exposure to nevirapine (years)

(1) Nevirapine

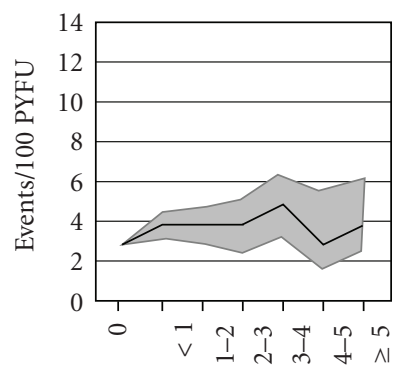

Exposure to efavirenz (years)

(m) Efavirenz

FIGURE 1: Incidence rates of myocardial infarction according to cumulative exposure to nucleoside/nucleotide analogues $(A-G)$, protease inhibitors $(H-K)$, and nonnucleoside reverse transcriptase inhibitors $(L, M)$. The grey areas indicate the $95 \%$ confidence interval. PYFU, person-years of followup. Adapted from Worm et al. [24].

\section{Pharmacologic Management of Dyslipidemia in HIV-Infected Subjects on HAART}

The Infectious Diseases Society of America (IDSA) and the European AIDS Clinical Society (EACS) have provided guidance for the treatment of dyslipidemia and the reduction of cardiovascular risk in patients with HIV infection [32, 33].

In general, patients with dyslipidemia and HIV infection should be treated in a manner similar to the general population $[47,48]$. Statins are recommended for patients 


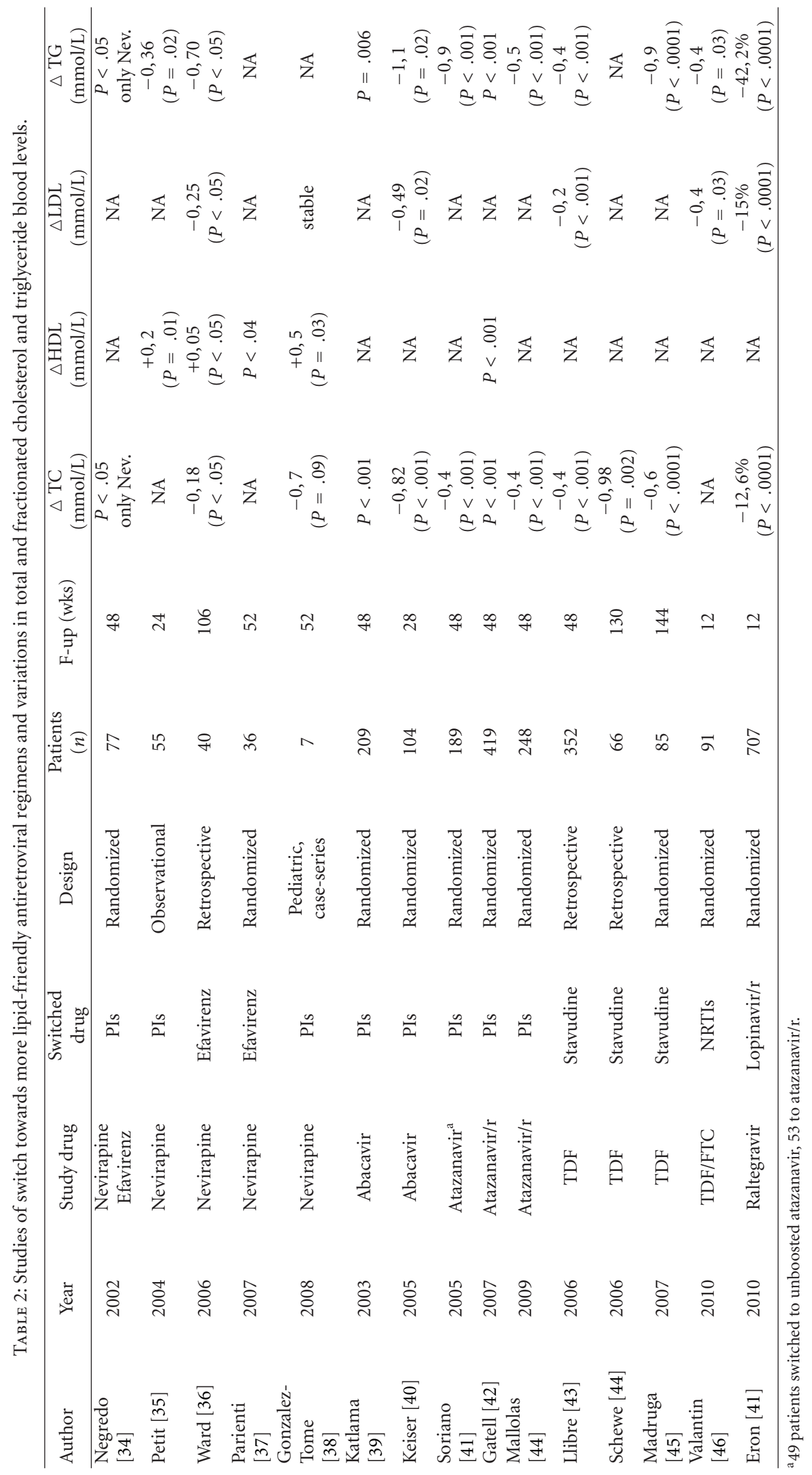


with hypercholesterolemia, although in patients receiving boosted PIs, they must be used with caution due to the high risk of interactions. For example, pravastatin levels have been shown to increase by $81 \%$ when given with boosted darunavir [49], whereas all other PIs tend to lower its levels. Simvastatin and lovastatin should be avoided in patients on PI-based regimens given the large and unpredictable increases in area under the curve (AUC) $[50,51]$. NNRTIs, namely, efavirenz, reduce the blood concentrations of simvastatin and atorvastatin [52]. Until now, pravastatin has been considered the "safest" to use in combination with boosted and unboosted PIs. Recently, also rosuvastatin levels have been shown to increase in HIV-seronegative subjects who are being treated with LPV/r [53]. In this study, the LDL-C responses to rosuvastatin during LPV/r coadministration were diminished despite the higher rosuvastatin levels observed, suggesting that the drug might be prevented from reaching the site of action (i.e., by efflux pumps). This observation has been confirmed in HIV-infected patients. The mean reductions in total cholesterol and LDL-C from baseline to week 4 on rosuvastatin $10 \mathrm{mg}$ once a day were $27.6 \%$ and $31.8 \%$, respectively [54]. A large randomized, double-blind, placebo-controlled, parallel group trial $(n=$ 320 ) with clinical endpoints is currently ongoing in the UK, evaluating the efficacy of rosuvastatin in slowing the progression of the carotid intima-media thickness (C-IMT; as measured by the change in the mean IMT of the near and far walls of the distal common carotid arteries), as well as its impact on hs-CRP, total and fractionated cholesterol, tryglicerides, and apolipoproteins (APO A1, APO B and APO B/A1) over 2 years in HIV-infected patients stable on antiretroviral therapy for at least 12 months having a 10 -year CVD risk lower than 20\% (using the Framingham risk score) [55]. Ezetimibe, a new inhibitor of intestinal absorption of cholesterol, has been shown to be safe and effective in HIVinfected patients [56-58].

When hypertriglyceridemia alone is present, often as a quite common side-effect of boosted PIs, gemfibrozil or fenofibrate are indicated, with minor drug interaction risks $[59,60]$. In some cases of mixed dyslipidemia, associating a statin and a fibrate may be the best approach for achieving NCEP ATP III lipid targets in patients with HIV infection, as shown in a recent study of pravastatin plus fenofibrate in HIV-infected subjects [61]. Study ACTG A5087 was a randomized trial of HIV-infected persons with combined hyperlipidemia who received fenofibrate or pravastatin monotherapy for 12 weeks followed by the association of both for up to 48 weeks in case of failure to meet NCEP goals for LDL-C, HDL-C, and triglyceride levels. Plasma levels of hs-CRP, lipoprotein particle and apolipoproteins A1/B, P-selectin (cell adhesion molecule), plasminogen activator inhibitor-1, and adiponectin were also monitored. The majority of subjects (60/74 chosen subjects) switched to dual therapy at week $12(n=32$, pravastatin added to fenofibrate monotherapy and $n=28$, fenofibrate added to pravastatin). Results showed that from baseline to week 12, adiponectin, apoB levels, and Apo B/A1 ratios all significantly decreased in the pravastatin and fenofibrate arms, whereas lipoprotein particle and Apo A1 increased significantly in the fenofibrate arm only $(P=.01$ for both measures). Combination therapy elicited improvements in lipid profiles without changes in the inflammatory and endothelial cell markers hs-CRP, plasminogen activator inhibitor-1, and $P$-selectin. From weeks 12-48, Apo B levels and Apo B/A1 ratios declined significantly in those subjects adding pravastatin to fenofibrate $(P<.01$ and $P=.01$, resp.), whereas adiponectin levels significantly decreased in both combination treatment groups. These investigators suggested that HIV infection or other comorbid infections may inhibit the anti-inflammatory effects associated with lipid-lowering agents in the general population.

A recent wide retrospective study on 829 patients with HIV infection and 6941 patients without HIV infection beginning lipid-lowering therapy for elevated low-density lipoprotein cholesterol or triglyceride levels from the Kaiser Permanente Cohort showed that overall the response to lipid-lowering agents in real life is worse in HIV-infected subjects. These had had smaller reductions in low-density lipoprotein cholesterol levels from statin therapy $(25.6 \%$ versus $28.3 \% ; P<.001$ ), which did not vary by antiretroviral therapy class. They also showed smaller reductions in triglyceride levels on gemfibrozil compared to patients without HIV infection $\left(44.2 \%\right.$ versus $\left.59.3 \% ; P_{-} .001\right)$, and reductions with gemfibrozil varied by antiretroviral therapy class $(44.0 \%$ $\left[P_{-} .001\right]$ in patients receiving PIs only, $26.4 \%\left[P_{-} .001\right]$ in patients receiving PIs and nonnucleoside reverse transcriptase inhibitors [NNRTIs], and 60.3\% $\left[P_{\text {_ }} .94\right]$ in patients receiving NNRTIs only). Rhabdomyolysis was diagnosed in 3 patients with HIV infection and 1 patient without HIV infection [62].

HIV-infected subjects often take fish oil supplements to control dyslipidemia, and some trials have confirmed their effect. In the A5186 prospective, phase 2 clinical trial study on 100 patients, twice-daily administration of fish oil supplement or once-daily fenofibrate reduced triglyceride levels by $283 \mathrm{mg} / \mathrm{dL}(46 \%)$ and $367 \mathrm{mg} / \mathrm{dL}(58 \%)$, respectively. Patients not responding to single medications were then treated subsequently with both agents showing a $65.5 \%$ reduction from baseline in triglyceride levels. With the combination therapy, $22.7 \%$ achieved triglyceride levels of $\leq 200 \mathrm{mg} / \mathrm{dL}$, starting from a median level of $667 \mathrm{mg} / \mathrm{dL}$ [63]. Lower reduction in serum triglycerides emerged from another randomized study versus placebo, where fish oil supplements at week 8 reduced triglycerides by $25.5 \%(n=$ $58)$ versus $1 \%$ in the paraffin oil control arm $(n=$ 62). The subsequent open-label phase showed sustained efficacy through 16-week continued treatment with fish oil supplement, while those switched placebo to fish oil supplement had a $21.2 \%$ decrease in serum triglycerides [64].

\section{Management of Dyslipidemia through Switch Strategies}

Another widespread approach among physicians is the switch to antiretroviral regimens characterized by low metabolic impact. In recent years, among others, an Italian team of experts set out recommendations on the diagnosis, 


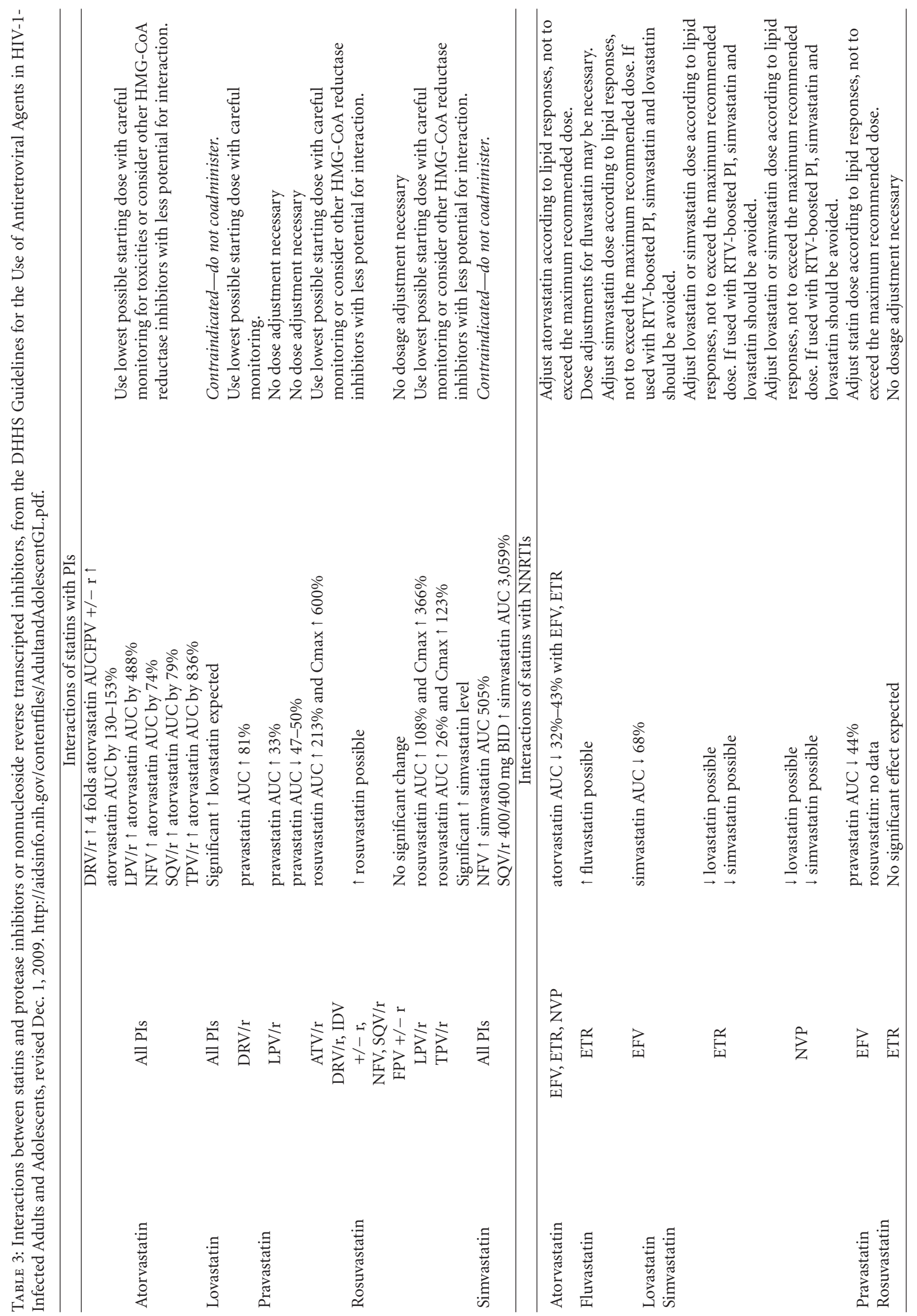


prevention, and treatment of cardiovascular complications in HIV-infected patients in the HAART era which included regimen switching rules to reduce the metabolic impact of drugs avoiding to expose the patients to virologic failure [65]. Indeed, particularly when substituting high-genetic barrier drugs such as boosted protease inhibitors, which can even work in cases of functional or true monotherapy, particular attention should be paid to the residual efficacy of the backbone (generally NRTIs), since the new drug would not have the same features, or, in the case of abacavir, might be directly affected by resistance to NRTIs. The most lipidfriendly drugs to switch to are abacavir, tenofovir, nevirapine, atazanavir, and most recently raltegravir and maraviroc. Unfortunately abacavir and maraviroc are currently charged with some suspicion of cardiac toxicity $[66,67]$. Trials on the switch to abacavir have constantly showed significant reductions in total and LDL cholesterol as well as in tryglicerides [68-70], and whenever patients are accurately selected for the absence of NRTI resistance-associated mutations or of previous NRTI failure, this simplification does not imply a higher risk of viral rebound [71]. Unfortunately, some studies have included patients pretreated with dual NRTI regimens which, presumably due to baseline resistance, showed a higher rate of virologic failure (3 versus 0/52 [68] and $13 \%$ versus $10 \%[72]$ ).

The simplification from an effective PI-based regimen to nevirapine generally proved to be safe and to improve the lipid profile, although sometimes some degree of hepatotoxicity was observed [73]. Lypodistrophy, however, is not reversed by the switch [74]. In a small 24-week insight study on 55 patients switched from a PI to nevirapine, the lipid profile improved with a significant reduction of apoB (from 0.98 to $0.92 \mathrm{~g} \mathrm{~L}(-1) ; P=.005)$ and triglycerides (from 2.02 to $1.66 \mathrm{mmol} \mathrm{L}(-1) ; P=.02)$. HDL cholesterol and apoA1 increased significantly (from 0.99 to $1.19 \mathrm{mmol} \mathrm{L}(-1) ; P=$ .001 and from 1.40 to $1.57 \mathrm{~g} \mathrm{~L}(-1) ; P<.001$, resp.). The triglyceride enrichment of HDL significantly decreased after the replacement of PI by nevirapine (from $0.248+/-0.092$ to $0.213+/-0.093 ; P=.003$ ), leading to a longer HDL half life. All such changes were correlated with adiponectin levels [75]. This simplification approach has yielded satisfactory results on the lipid profile of children as well [76]. No excess failures were reported with nevirapine and in some cases this strategy maintained better virologic suppression at 12 months. [73] More recently, switch from efavirenz to nevirapine has also become a relevant hypothesis, since the former has always shown to be unable to revert PI-induced metabolic alterations [77] and has been associated with a certain degree of such side effects. Switching to nevirapine in such reports was associated with decreases in LDLCholesterol and increases in HDL, as well as with a reduction of neuropsychiatric effects $[40,78]$. Viral suppression was maintained in all switchers and in one study also two initially viremic patients suppressed passing to nevirapine [78].

Switches to tenofovir from thymidine analogues [39], mainly stavudine [34, 79-81], have showed some good changes in the lipid profile. In particular, a study on 352 HIVinfected subjects followed for 48 weeks found a sustained reduction in median TC $(-17.5 \mathrm{mg} / \mathrm{dL} ; P<.001)$, LDLC $(-8.1 \mathrm{mg} / \mathrm{dL} ; P<.001)$, and TG $(-35 \mathrm{mg} / \mathrm{dL} ; P<$ $.001)$. HDL-C remained roughly unchanged $(-0.8 \mathrm{mg} / \mathrm{dL})$. Patients with baseline hyperlipidaemia showed greater reductions in LDL-C $(-29 \mathrm{mg} / \mathrm{dL} ; P<.001)$ and TG $(-76 \mathrm{mg} / \mathrm{dL} ; P<.001)$. The greatest TG reduction was observed in patients with severe hypertrygliceridaemia $(-266 \mathrm{mg} / \mathrm{dL} ; P<.001)$. The estimated 10 -year cardiovascular risk decreased in all patients $(P<.001)$ and to a higher extent in patients with baseline hyperlipidaemia. There was a trend towards reduction according to the use of lipidlowering agents ( $11.6 \%$ to $9,9 \%$; $P=$ nonsignificant) [35]. However, the beneficial effect sought by many on mitochondrial damage and lipodystrophy is still controversial $[38,82]$, with the reduction of lactataemia in those patients who started from elevated serum lactates being the only constant finding. This switch provided good metabolic effect also in children although the data are biased by a contemporary substitution of efavirenz for PIs [36]. The switch from thymidine analogues to tenofovir is safe and no virological failures have been reported in the studies performed up to date.

In recent years, the most studied simplification approach remains within the family of protease inhibitors and concerns atazanavir, a lipid-friendly compound. All the trials demonstrated a decline in total cholesterol and tryglicerides, in particular the large SWAN [37], SLOAT [46], and ATAZIP trials [44], but when a deeper look was brought, also HDL cholesterol tended to decrease [45] or remained stable [83], showing in this respect a difference from nevirapine simplification. Most recently it has been suggested that even the low dose ritonavir present in the boosted atazanavirbased regimens may do or maintain some metabolic harm and that the switch to unboosted atazanavir in virologically suppressed patients without resistance-associated mutations is associated with a more favourable lipid profile without risks of loosing the grip on HIV, and a large trial seems to confirm these data [84]. A small pilot study of 9 patients with dyslipidemia and insulin resistance, tested through hyperinsulinemic euglycemic clamp (insulin dose, $200 \mathrm{mU} / \mathrm{m}$ minute), showed in all a relevant increase in insulin sensitivity $(+28 \%$; $P=.008) 12$ months after the switch from a PI to boosted atazanavir [43]. However, two studies looked at endothelial function, through the measurement of the brachial artery flow-mediated dilation and at various inflammatory and oxidative stress markers in subjects switching to boosted atazanavir and unfortunately found no difference between baseline and week 12 and 24 values [85, 86]. Another study looking at age-related cardiovascular risk found a very limited impact by this approach, mainly due to the presence of other relevant and unchanged risk factors [87]. Overall, simplification with atazanavir does not alter viral response, some studies are showing slightly better control with the switch and others moderately favour the continuation arms.

An attempt to exclude nucleoside analogues by building a PI plus NNRTI regimen in the ACTG 5125 extension trial maintained viral suppression but worsened the lipid profile 
of the patients [42]. On the contrary, in the Switchmrk study, the randomized substitution of lopinavir/ritonavir with the integrase inhibitor raltegravir yielded an important drop in serum levels of total cholesterol $(-12.6 \%$ versus $1.0 \%$ in those who did not switch), non-HDL cholesterol $(-15.0 \%$ versus $2.6 \%)$, and triglycerides ( $-42.2 \%$ versus $6.2 \%)$ in 350 subjects in only 12 weeks [41]. Unfortunately, the inclusion of patients who did not have a fully effective NRTI backbone negatively impacted on the achievement of the noninferiority goal: at week $24,84,4 \%$ of the patients switched to raltegravir maintained a viral load $<50$ copies $/ \mathrm{mL}$ versus $90,6 \%$ in the lopinavir continuation arm.

\section{Conclusions}

CVD risk in HIV infection results from the combination of the effects of host and viral factors and antiretroviral therapy. Antiretroviral therapy has been shown to reduce HIV-related inflammation, and in some studies also to reduce the impact of CVD. The most recent revisions of international guidelines for the use of antiretroviral agents have predated the decision to start therapy at earlier stages of the infection, to reduce non-HIV-related morbidity and mortality, mainly related to tumours and CVD.

Understanding the differences between antiretroviral drugs with regard to lipid alterations, acceleration of atherosclerosis, and CVD risk is crucial to plan regimens that are to be maintained for decades.

The capacity to tailor antiretroviral therapy designed on individual characteristic and CVD risk profile awaits attention and ability to balance risk and benefit of antiretroviral therapy. The clinical impact of the QT prolongation by many antiretrovirals has not been fully elucidated up to date.

Finally, much work remains to be done in understanding the mechanisms of the risk posed by therapy and by HIV itself and the new antiretroviral drugs should not be considered safe a priori, as unexpected impact on CVD has emerged in some cases after many years.

Recently, four new agents from four classes have been given approval in the US and Canada for use in HIV-infected persons. Two of these drugs (maraviroc and raltegravir) were the first of their respective classes (integrase inhibitors and CCR5 inhibitors) to be approved. In addition, another drug, rilpivirine, is in clinical trial Phase III.

Rilpivirine appears to be associated with lower rates of lipid elevations than efavirenz; although theoretically the inhibition of the CCR5 coreceptor seems protective of CVD, in the MOTIVATE study, the maraviroc arm was associated with more CVD events.

Raltegravir has not shown up to date any particular impact on lipids or on CVD, while etravirine and darunavir also seem more lipid-friendly than many other agents.

However, all these data are theoretical and do not fully answer to the fundamental question: in future years, starting therapy earlier, will the balance of CVD in HIV-infected patients be positive, due to the reduction of HIV-related damage, or negative, due to the cardiovascular impact of drugs that we may not fully appreciate today?

\section{References}

[1] J. Danesh, R. Collins, and R. Peto, "Chronic infections and coronary heart disease: is there a link?" The Lancet, vol. 350, no. 9075 , pp. 430-436, 1997.

[2] K. J. Mattila, V. V. Valtonen, M. S. Nieminen, and S. Asikainen, "Role of infection as a risk factor for atherosclerosis, myocardial infarction, and stroke," Clinical Infectious Diseases, vol. 26, no. 3, pp. 719-734, 1998.

[3] S. E. Epstein, Y. F. Zhou, and J. Zhu, "Infection and atherosclerosis: emerging mechanistic paradigms," Circulation, vol. 100, no. 4, pp. e20-e28, 1999.

[4] C. R. Meier, S. S. Jick, L. E. Derby, C. Vasilakis, and H. Jick, "Acute respiratory-tract infections and risk of first-time acute myocardial infarction," The Lancet, vol. 351, no. 9114, pp. 1467-1471, 1998.

[5] C. Grunfeld and K. R. Feingold, "Tumor necrosis factor, interleukin, and interferon induced changes in lipid metabolism as part of host defense," Proceedings of the Society for Experimental Biology and Medicine, vol. 200, no. 2, pp. 224-227, 1992.

[6] M. Leinonen and P. Saikku, "Evidence for infectious agents in cardiovascular disease and atherosclerosis," Lancet Infectious Diseases, vol. 2, no. 1, pp. 11-17, 2002.

[7] J. Zhu, A. A. Quyyumi, J. E. Norman et al., "Effects of total pathogen burden on coronary artery disease risk and Creactive protein levels," American Journal of Cardiology, vol. 85, no. 2, pp. 140-146, 2000.

[8] M. Roivainen, G. Alfthan, P. Jousilahti, M. Kimpimäki, T. Hovi, and J. Tuomilehto, "Enterovirus infections as a possible risk factor for myocardial infarction," Circulation, vol. 98, no. 23, pp. 2534-2537, 1998.

[9] L. Broxmeyer, "Heart disease: the greatest 'risk' factor of them all," Medical Hypotheses, vol. 62, no. 5, pp. 773-779, 2004.

[10] S. Rasheed, J. S. Yan, A. Lau, and A. S. Chan, "HIV replication enhances production of free fatty acids, low density lipoproteins and many key proteins involved in lipid metabolism: a proteomics study," PLoS ONE, vol. 3, no. 8, Article ID e3003, 2008.

[11] M. K. Hellerstein, C. Grunfeld, K. Wu et al., "Increased de novo hepatic lipogenesis in human immunodeficiency virus infection," Journal of Clinical Endocrinology and Metabolism, vol. 76, no. 3, pp. 559-565, 1993.

[12] S. A. Riddler, E. Smit, S. R. Cole et al., "Impact of HIV infection and HAART on serum lipids in men," Journal of the American Medical Association, vol. 289, no. 22, pp. 2978-2982, 2003.

[13] J. L. Anderson, "Infection, antibiotics, and atherothrombosis - end of the road or new beginnings?" The New England Journal of Medicine, vol. 352, no. 16, pp. 1706-1709, 2005.

[14] C. Cicognani, M. Malavolti, A. M. Morselli-Labate, L. Zamboni, C. Sama, and L. Barbara, "Serum lipid and lipoprotein patterns in patients with liver cirrhosis and chronic active hepatitis," Archives of Internal Medicine, vol. 157, no. 7, pp. 792-796, 1997.

[15] J. S. Currier, J. D. Lundgren, A. Carr et al., "Epidemiological evidence for cardiovascular disease in HIV-infected patients and relationship to highly active antiretroviral therapy," Circulation, vol. 118, no. 2, pp. e29-e35, 2008.

[16] S. Lai, E. K. Fishman, H. Lai et al., "Long-term cocaine use and antiretroviral therapy are associated with silent coronary artery disease in African Americans with HIV infection who have no cardiovascular symptoms," Clinical Infectious Diseases, vol. 46, no. 4, pp. 600-610, 2008. 
[17] E. Martínez, A. Milinkovic, E. Buira et al., "Incidence and causes of death in HIV-infected persons receiving highly active antiretroviral therapy compared with estimates for the general population of similar age and from the same geographical area," HIV Medicine, vol. 8, no. 4, pp. 251-258, 2007.

[18] E. A. Eugenin, S. Morgello, M. E. Klotman et al., "Human immunodeficiency virus (HIV) infects human arterial smooth muscle cells in vivo and in vitro: implications for the pathogenesis of HIV-mediated vascular disease," American Journal of Pathology, vol. 172, no. 4, pp. 1100-1111, 2008.

[19] F. J. Torriani, L. Komarow, R. A. Parker et al., "Endothelial function in human immunodeficiency virus-infected antiretroviral-naive subjects before and after starting potent antiretroviral therapy. The ACTG (AIDS Clinical Trials Group) study 5152s," Journal of the American College of Cardiology, vol. 52, no. 7, pp. 569-576, 2008.

[20] D. Francisci, S. Giannini, F. Baldelli et al., "HIV type 1 infection, and not short-term HAART, induces endothelial dysfunction,” AIDS, vol. 23, no. 5, pp. 589-596, 2009.

[21] SMART Study Group, "CD4+-guided interruption of antiretroviral treatment," The New England Journal of Medicine, vol. 355, pp. 2283-2296, 2006.

[22] P. Tebas, W. K. Henry, R. Matining et al., "Metabolic and immune activation effects of treatment interruption in chronic HIV-1 infection: implications for cardiovascular risk," PLoS ONE, vol. 3, no. 4, Article ID e2021, 2008.

[23] N. Friis-Møller, P. Reiss, C. A. Sabin et al., "Class of antiretroviral drugs and the risk of myocardial infarction," The New England Journal of Medicine, vol. 356, no. 17, pp. 17231735, 2007.

[24] S. W. Worm, C. Sabin, R. Weber et al., "Risk of myocardial infarction in patients with HIV infection exposed to specific individual antiretroviral drugs from the 3 major drug classes: the data collection on adverse events of anti-HIV drugs (D:A:D) study," Journal of Infectious Diseases, vol. 201, no. 3, pp. 318-330, 2010.

[25] D. Cooper, M. Bloch, A. Humphries et al., "Simplification with fixed-dose Tenofovir/Emtricitabine or Abacavir/Lamivudine in adults with suppressed HIV replication: the STEAL study, a randomized, open-label, 96-week, non-inferiority trial," in Proceedings of the 16th Conference on Retroviruses and. Opportunistic Infections (CROI '10), Montréal, Canada, February 2009, abstract no. 576.

[26] E. Martínez, J. A. Arranz, D. Podzamczer et al., "A simplification trial switching from nucleoside reverse transcriptase inhibitors to once-daily fixed-dose abacavir/lamivudine or tenofovir/ emtricitabine in HIV-1-infected patients with virological suppression," Journal of Acquired Immune Deficiency Syndromes, vol. 51, no. 3, pp. 290-297, 2009.

[27] P. E. Sax, C. Tierney, A. C. Collier et al., "Abacavir-lamivudine versus tenofovir-emtricitabine for initial HIV-1 therapy," The New England Journal of Medicine, vol. 361, no. 23, pp. 2230 2240, 2009.

[28] S. Walmsley, A. Avihingsanon, J. Slim et al., "Gemini: a noninferiority study of saquinavir/ritonavir versus lopinavir/ritonavir as initial HIV-I therapy in adults," Journal of Acquired Immune Deficiency Syndromes, vol. 50, no. 4, pp. 367-374, 2009.

[29] J. Eron Jr., P. Yeni, J. Gathe Jr. et al., "The KLEAN study of fosamprenavir-ritonavir versus lopinavir-ritonavir, each in combination with abacavir-lamivudine, for initial treatment of HIV infection over 48 weeks: a randomised non-inferiority trial," The Lancet, vol. 368, no. 9534, pp. 476-482, 2006.
[30] J.-M. Molina, J. Andrade-Villanueva, J. Echevarria et al., "Once-daily atazanavir/ritonavir compared with twice-daily lopinavir/ritonavir, each in combination with tenofovir and emtricitabine, for management of antiretroviral-naïve HIV1-infected patients: 96-week efficacy and safety results of the CASTLE study," Journal of Acquired Immune Deficiency Syndromes, vol. 53, no. 3, pp. 323-332, 2010.

[31] A. M. Mills, M. Nelson, D. Jayaweera et al., "Once-daily darunavir/ritonavir vs. lopinavir/ritonavir in treatment-naive, HIV-1-infected patients: 96-week analysis," AIDS, vol. 23, no. 13, pp. 1679-1688, 2009.

[32] M. P. Dubé, J. H. Stein, J. A. Aberg et al., "Guidelines for the evaluation and management of dyslipidemia in human immunodeficiency virus (HIV)-infected adults receiving antiretroviral therapy: recommendations of the HIV Medicine Association of the Infectious Disease Society of America and the Adult AIDS Clinical Trials Group," Clinical Infectious Diseases, vol. 37, no. 5, pp. 613-627, 2003.

[33] http://www.europeanaidsclinicalsociety.org /guidelinespdf/1_Treatment_of_HIV_Infected_Adults.pdf.

[34] A. Milinkovic, E. Martinez, S. López et al., "The impact of reducing stavudine dose versus switching to tenofovir on plasma lipids, body composition and mitochondrial function in HIV-infected patients," Antiviral Therapy, vol. 12, no. 3, pp. 407-415, 2007.

[35] J. M. Llibre, P. Domingo, R. Palacios et al., "Sustained improvement of dyslipidaemia in HAART-treated patients replacing stavudine with tenofovir," AIDS, vol. 20, no. 10, pp. 1407-1414, 2006.

[36] A. Viganò, G. M. Aldrovandi, V. Giacomet et al., "Improvement in dyslipidaemia after switching stavudine to tenofovir and replacing protease inhibitors with efavirenz in HIVinfected children," Antiviral Therapy, vol. 10, no. 8, pp. 917924, 2005.

[37] D. Salmon-Ceron, A. Lazzarin, E. Van Wijngaerden et al., "Efficacy and safety of atazanavir-based highly active antiretroviral therapy in patients with virologic suppression switched from a stable, boosted or unboosted protease inhibitor treatment regimen: the SWAN study (AI424-097) 48-week results," Clinical Infectious Diseases, vol. 44, no. 11, pp. 1484-1492, 2007.

[38] G. J. Class, B. Jülg, J. Röling, F. D. Goebel, and J. R. Bogner, "Metabolic and anthropometric changes one year after switching from Didanosine/Stavudine to Tenofovir in HIV-infected patients," European Journal of Medical Research, vol. 12, no. 2, pp. 54-60, 2007.

[39] M. A. Valantin, R. Bittar, P. de Truchis et al., "Switching the nucleoside reverse transcriptase inhibitor backbone to tenofovir disoproxil fumarate+emtricitabine promptly improves triglycerides and low-density lipoprotein cholesterol in dyslipidaemic patients," Journal of Antimicrobial Chemotherapy, vol. 65, no. 3, pp. 556-561, 2010.

[40] J.-J. Parienti, V. Massari, D. Rey, P. Poubeau, and R. Verdon, "Efavirenz to nevirapine switch in HIV-1-infected patients with dyslipidemia: a randomized, controlled study," Clinical Infectious Diseases, vol. 45, no. 2, pp. 263-266, 2007.

[41] J. J. Eron, B. Young, D. A. Cooper et al., "Switch to a raltegravir-based regimen versus continuation of a lopinavirritonavir-based regimen in stable HIV-infected patients with suppressed viraemia (SWITCHMRK 1 and 2): two multicentre, double-blind, randomised controlled trials," The Lancet, vol. 375, no. 9712, pp. 396-407, 2010.

[42] P. Tebas, J. Zhang, K. Yarasheski et al., "Switching to a protease inhibitor-containing, nucleoside-sparing regimen 
(lopinavir/ritonavir plus efavirenz) increases limb fat but raises serum lipid levels: results of a prospective randomized trial (AIDS clinical trial group 5125s)," Journal of Acquired Immune Deficiency Syndromes, vol. 45, no. 2, pp. 193-200, 2007.

[43] A. J. Busti, R. Bedimo, D. M. Margolis, and D. S. Hardin, "Improvement in insulin sensitivity and dyslipidemia in protease inhibitor-treated adult male patients after switch to atazanavir/ritonavir," Journal of Investigative Medicine, vol. 56, no. 2, pp. 539-544, 2008.

[44] J. Mallolas, D. Podzamczer, A. Milinkovic et al., "Efficacy and safety of switching from boosted lopinavir to boosted atazanavir in patients with virological suppression receiving a lpv/r-containing haart: the atazip study," Journal of Acquired Immune Deficiency Syndromes, vol. 51, no. 1, pp. 29-36, 2009.

[45] S. T. Nguyen, S. A. Eaton, A. M. Bain et al., "Lipid-lowering efficacy and safety after switching to atazanavir-ritonavirbased highly active antiretroviral therapy in patients with human immunodeficiency virus," Pharmacotherapy, vol. 28, no. 3, pp. 323-330, 2008.

[46] V. Soriano, P. García-Gasco, E. Vispo et al., "Efficacy and safety of replacing lopinavir with atazanavir in HIV-infected patients with undetectable plasma viraemia: final results of the SLOAT trial," Journal of Antimicrobial Chemotherapy, vol. 61, no. 1, pp. 200-205, 2008.

[47] J. I. Cleeman, "Executive summary of the third report of the National Cholesterol Education Program (NCEP) expert panel on detection, evaluation, and treatment of high blood cholesterol in adults (adult treatment panel III)," Journal of the American Medical Association, vol. 285, no. 19, pp. 2486-2497, 2001.

[48] M. Tungsiripat and J. A. Aberg, "Dyslipidemia in HIV patients," Cleveland Clinic Journal of Medicine, vol. 72, no. 12, pp. 1113-1120, 2005.

[49] V. Sekar, S. Spinosa-Guzman, and K. Marien, "Pharmacokinetic drug-drug interaction between the new HIV protease inhibitor darunavir (TMC114) and the lipid-lowering agent pravastatin," in Proceedings of the 8th International Workshop on Clinical Pharmacology of HIV Therapy, Budapest, Hungary, April 2007, abstract no. 54.

[50] C. J. Fichtenbaum and J. G. Gerber, "Interactions between antiretroviral drugs and drugs used for the therapy of the metabolic complications encountered during HIV infection," Clinical Pharmacokinetics, vol. 41, no. 14, pp. 1195-1211, 2002.

[51] G. J. Moyle, M. Lloyd, B. Reynolds, C. Baldwin, S. Mandalia, and B. G. Gazzard, "Dietary advice with or without pravastatin for the management of hypercholesterolaemia associated with protease inhibitor therapy," AIDS, vol. 15, no. 12, pp. 1503$1508,2001$.

[52] J. G. Gerber, S. L. Rosenkranz, C. J. Fichtenbaum et al., "Effect of efavirenz on the pharmacokinetics of simvastatin, atorvastatin, and pravastatin: results of AIDS clinical trials group 5108 study," Journal of Acquired Immune Deficiency Syndromes, vol. 39, no. 3, pp. 307-312, 2005.

[53] J. J. Kiser, J. G. Gerber, J. A. Predhomme, P. Wolfe, D. M. Flynn, and D. W. Hoody, "Drug/drug interaction between lopinavir/ritonavir and rosuvastatin in healthy volunteers," Journal of Acquired Immune Deficiency Syndromes, vol. 47, no. 5, pp. 570-578, 2008.

[54] M. van der Lee, R. Sankatsing, E. Schippers et al., "Pharmacokinetics and pharmacodynamics of combined use of lopinavir/ritonavir and rosuvastatin in HIV-infected patients," Antiviral Therapy, vol. 12, no. 7, pp. 1127-1132, 2007.
[55] F. De Lorenzo, M. Boffito, S. Collot-Teixeira et al., "Prevention of atherosclerosis in patients living with HIV," Vascular Health and Risk Management, vol. 5, no. 1, pp. 287-300, 2009.

[56] E. Negredo, J. Moltó, J. Puig et al., "Ezetimibe, a promising lipid-lowering agent for the treatment of dyslipidaemia in HIV-infected patients with poor response to statins," AIDS, vol. 20, no. 17, pp. 2159-2164, 2006.

[57] D. Wohl, P. Hsue, S. Richard et al., "Ezetimibe's effects on the LDL cholesterol levels of HIV-infected patients receiving HAART," in Proceedings of the 14th Conference on Retroviruses and. Opportunistic Infections (CROI '07), Los Angeles, Calif, USA, 2007, abstract no. 39.

[58] M. T. Bennett, K. W. Johns, and G. P. Bondy, "Ezetimibe is effective when added to maximally tolerated lipid lowering therapy in patients with HIV," Lipids in Health and Disease, vol. 6, Article ID 15, 2007.

[59] J. Miller, D. Brown, J. Amin et al., "A randomized, doubleblind study of gemfibrozil for the treatment of protease inhibitor-associated hypertriglyceridaemia," AIDS, vol. 16, no. 16, pp. 2195-2200, 2002.

[60] J. A. Aberg, R. A. Zackin, S. W. Brobst et al., "A randomized trial of the efficacy and safety of fenofibrate versus pravastatin in HIV-infected subjects with lipid abnormalities: AIDS Clinical Trials Group study 5087," AIDS Research and Human Retroviruses, vol. 21, no. 9, pp. 757-767, 2005.

[61] C. J. Fichtenbaum, T.-M. Yeh, S. R. Evans et al., "Changes in markers of atherogenic dyslipidemia, inflammation, and platelet activation with treatment with pravastatin, fenofibrate, or the combination: results from ACTG A5087," in Proceedings of the 15th Conference on Retroviruses and. Opportunistic Infections (CROI '08), Boston, Mass, USA, 2008, abstract no. 932.

[62] M. J. Silverberg, W. Levden, L. Hurley et al., "Response to newly prescribed lipid-lowering therapy in patients with and without HIV infection," Annals of Internal Medicine, vol. 150, no. 5, pp. 301-313, 2009.

[63] J. G. Gerber, D. W. Kitch, C. J. Fichtenbaum et al., "Fish oil and fenofibrate for the treatment of hypertriglyceridemia in HIVinfected subjects on antiretroviral therapy: results of ACTG A5186," Journal of Acquired Immune Deficiency Syndromes, vol. 47, no. 4, pp. 459-466, 2008.

[64] P. De Truchis, M. Kirstetter, A. Perier et al., "Reduction in triglyceride level with N-3 polyunsaturated fatty acids in HIV-infected patients taking potent antiretroviral therapy: a randomized prospective study," Journal of Acquired Immune Deficiency Syndromes, vol. 44, no. 3, pp. 278-285, 2007.

[65] G. Carosi, E. Quiros-Roldan, C. Torti et al., "First Italian consensus statement on diagnosis, prevention and treatment of cardiovascular complications in HIV-infected patients in the HAART era (2006)," Infection, vol. 35, no. 3, pp. 134-142, 2007.

[66] G. M. N. Behrens and P. Reiss, "Abacavir and cardiovascular risk," Current Opinion in Infectious Diseases, vol. 23, no. 1, pp. 9-14, 2010.

[67] J. R. Arribas López, "Secondary effects of treatment with maraviroc and other CCR5 antagonists. Potential impact of the CCR5 blocker," Enfermedades Infecciosas y Microbiología Clínica, vol. 26, supplement 11, pp. 23-27, 2008.

[68] P. H. Keiser, M. G. Sension, E. DeJesus et al., "Substituting abacavir for hyperlipidemia-associated protease inhibitors in HAART regimens improves fasting lipid profiles, maintains virologic suppression, and simplifies treatment," BMC Infectious Diseases, vol. 5, no. 1, article 2, 2005. 
[69] C. Katlama, B. Gazzard, J. Mallolas et al., "Comparison of metabolic abnormalities 48 weeks after switching from highly active antiretroviral therapy containing a non-nucleoside reverse transcriptase inhibitor to Trizivir versus continued highly active antiretroviral therapy," AIDS, vol. 17, no. 12, pp. 1855-1856, 2003.

[70] A. Lafeuillade, N. Clumeck, J. Mallolas et al., "Comparison of metabolic abnormalities and clinical lipodystrophy 48 weeks after switching from HAART to Trizivir versus continued HAART: the trizal study," HIV Clinical Trials, vol. 4, no. 1, pp. 37-43, 2003.

[71] G. Rizzardini and A. Capetti, "Switch to abacavir-based triple nucleoside regimens in HIV-1 infected patients never treated with suboptimal antiretroviral therapy: a review," Medical Science Monitor, vol. 12, no. 12, pp. RA269-RA276, 2006.

[72] E. Martínez, J. A. Arnaiz, D. Podzamczer et al., "Substitution of nevirapine, efavirenz, or abacavir for protease inhibitors in patients with human immunodeficiency virus infection," The New England Journal of Medicine, vol. 349, no. 11, pp. 10361046, 2003.

[73] E. Negredo, L. Cruz, R. Paredes et al., "Virological, immunological, and clinical impact of switching from protease inhibitors to nevirapine or to efavirenz in patients with human immunodeficiency virus infection and long-lasting viral suppression," Clinical Infectious Diseases, vol. 34, no. 4, pp. 504-510, 2002.

[74] L. Ruiz, E. Negredo, P. Domingo et al., "Antiretroviral treatment simplification with nevirapine in protease inhibitorexperienced patients with HIV-associated lipodystrophy: 1year prospective follow-up of a multicenter, randomized, controlled study," Journal of Acquired Immune Deficiency Syndromes, vol. 27, no. 3, pp. 229-236, 2001.

[75] J. M. Petit, M. Duong, D. Masson et al., "Serum adiponectin and metabolic parameters in HIV-I-infected patients after substitution of nevirapine for protease inhibitors," European Journal of Clinical Investigation, vol. 34, no. 8, pp. 569-575, 2004.

[76] M. I. Gonzalez-Tome, J. T. R. Amador, J. M. Peña, M. L. N. Gomez, P. R. Conejo, and P. M. Fontelos, "Outcome of protease inhibitor substitution with nevirapine in HIV-1 infected children," BMC Infectious Diseases, vol. 8, Article ID 144, 2008.

[77] V. Estrada, N. G. P. De Villar, M. T. M. Larrad, A. G. López, C. Fernández, and M. Serrano-Rios, "Long-term metabolic consequences of switching from protease inhibitors to efavirenz in therapy for human immunodeficiency virusinfected patients with lipoatrophy," Clinical Infectious Diseases, vol. 35, no. 1, pp. 69-76, 2002.

[78] D. J. Ward and J. M. Curtin, "Switch from efavirenz to nevirapine associated with resolution of efavirenz-related neuropsychiatric adverse events and improvement in lipid profiles," AIDS Patient Care and STDs, vol. 20, no. 8, pp. 542$548,2006$.

[79] C. K. Schewe, R. Maserati, G. Wassmer, A. Adam, and L. Weitner, "Improved lipid profiles and maintenance of virologic control in heavily pretreated hiv-infected patients who switched from stavudine to tenofovir treatment," Clinical Infectious Diseases, vol. 42, no. 1, pp. 145-147, 2006.

[80] J. V. R. Madruga, I. Cassetti, J. M. A. H. Suleiman et al., "The safety and efficacy of switching stavudine to tenofovir DF in combination with lamivudine and efavirenz in HIV-1-infected patients: three-year follow-up after switching therapy," HIV Clinical Trials, vol. 8, no. 6, pp. 381-390, 2007.
[81] J. Ananworanich, R. Nuesch, H. C. F. Côté et al., "Changes in metabolic toxicity after switching from stavudine/didanosine to tenofovir/lamivudine- a staccato trial substudy," Journal of Antimicrobial Chemotherapy, vol. 61, no. 6, pp. 1340-1343, 2008.

[82] E. Ribera, J. C. Paradiñeiro, A. Curran et al., "Improvements in subcutaneous fat, lipid profile, and parameters of mitochondrial toxicity in patients with peripheral lipoatrophy when stavudine is switched to tenofovir (LIPOTEST Study)," HIV Clinical Trials, vol. 9, no. 6, pp. 407-417, 2008.

[83] U. Möbius, M. Lubach-Ruitman, B. Castro-Frenzel et al., "Switching to atazanavir improves metabolic disorders in antiretroviral-experienced patients with severe hyperlipidemia," Journal of Acquired Immune Deficiency Syndromes, vol. 39, no. 2, pp. 174-180, 2005.

[84] M. Sension, J. L. De Andrade Neto, B. Grinsztejn et al., "Improvement in lipid profiles in antiretroviral-experienced HIV-positive patients with hyperlipidemia after a switch to unboosted atazanavir," Journal of Acquired Immune Deficiency Syndromes, vol. 51, no. 2, pp. 153-162, 2009.

[85] A. J. Flammer, N. T. T. Vo, B. Ledergerber et al., "Effect of atazanavir versus other protease inhibitor-containing antiretroviral therapy on endothelial function in HIV-infected persons: randomised controlled trial," Heart, vol. 95, no. 5, pp. 385-390, 2009.

[86] R. L. Murphy, B. Berzins, C. Zala et al., "Change to atazanavir/ritonavir treatment improves lipids but not endothelial function in patients on stable antiretroviral therapy," AIDS, vol. 24, no. 6, pp. 885-890, 2010.

[87] M. Colafigli, S. Di Giambenedetto, L. Bracciale, E. Tamburrini, R. Cauda, and A. De Luca, "Cardiovascular risk score change in HIV-1-infected patients switched to an atazanavir-based combination antiretroviral regimen," HIV Medicine, vol. 9, no. 3, pp. 172-179, 2008. 


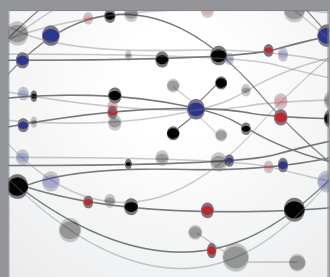

The Scientific World Journal
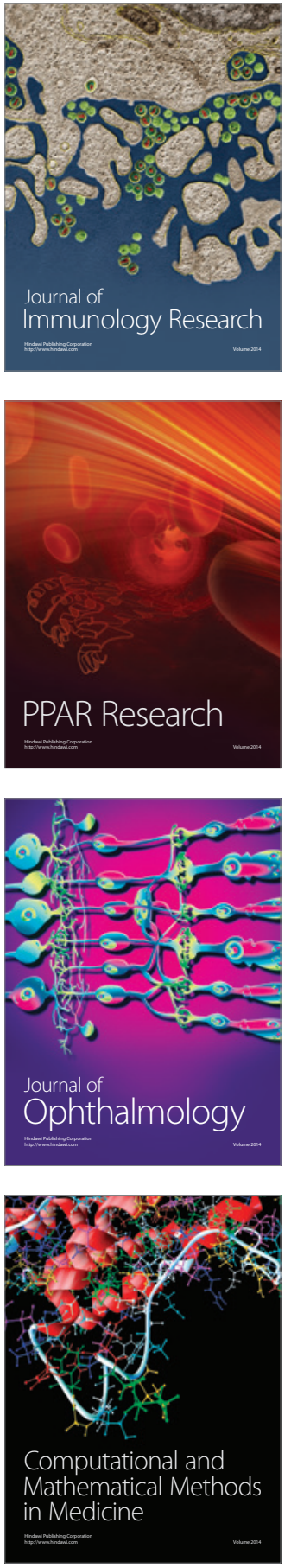

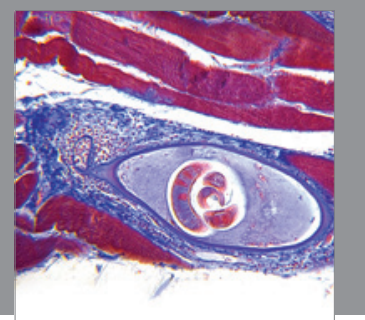

Gastroenterology

Research and Practice
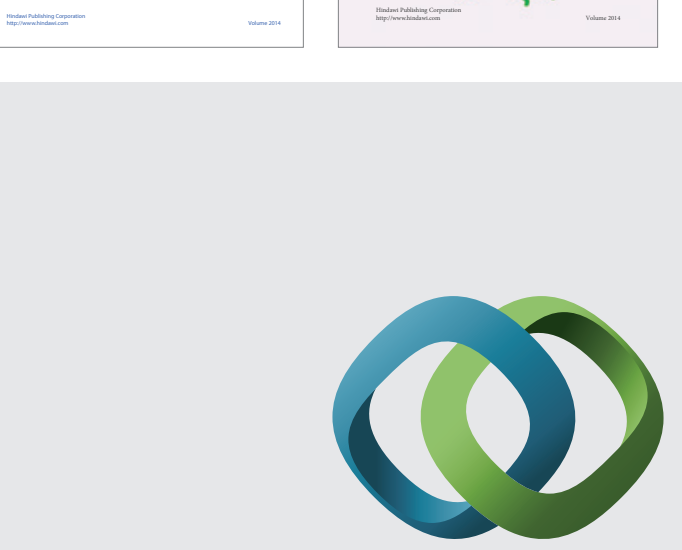

\section{Hindawi}

Submit your manuscripts at

http://www.hindawi.com
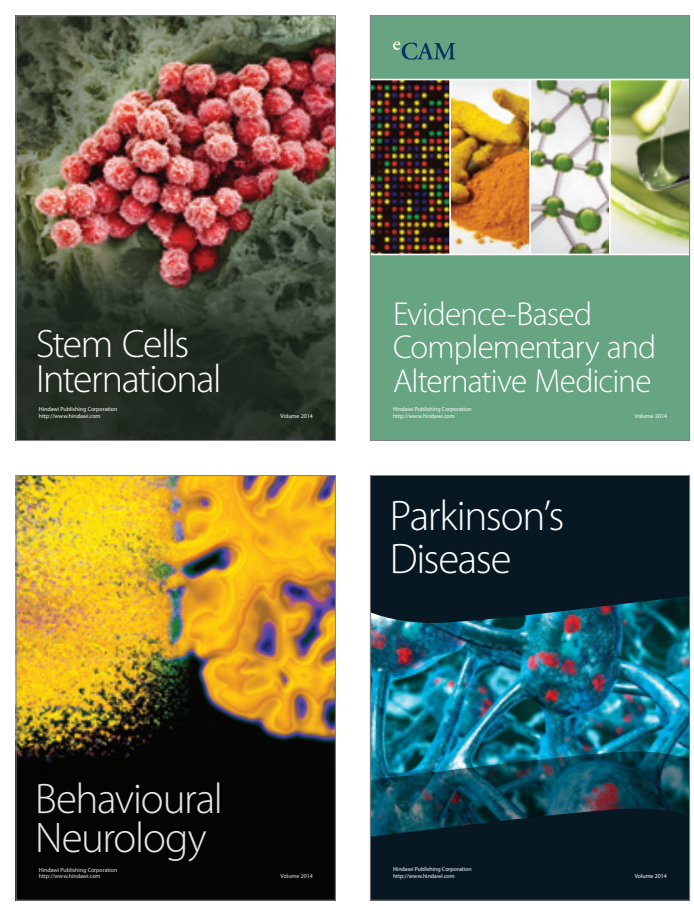

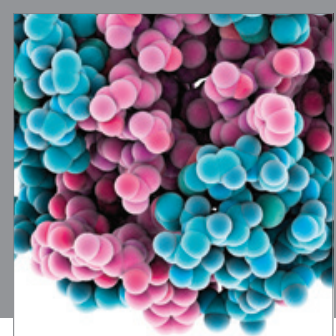

Journal of
Diabetes Research

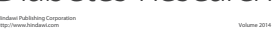

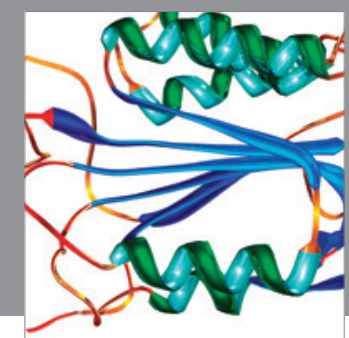

Disease Markers
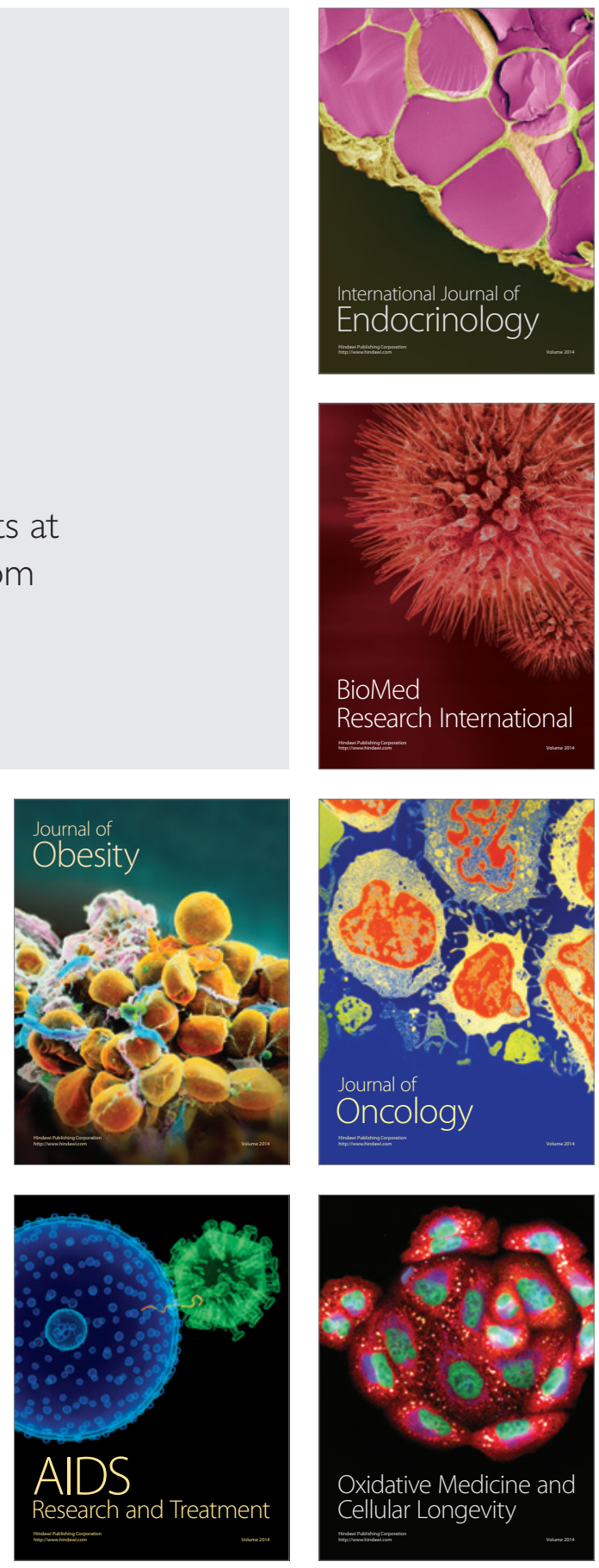